\title{
Protection of a New Heptapeptide from Carapax trionycis against Carbon Tetrachloride-Induced Acute Liver Injury in Mice
}

\author{
Penglong Wang, ${ }^{a}$ Yuzhong Zhang, ${ }^{b}$ Yawen $\mathrm{An},{ }^{a, c} \mathrm{Kuo} \mathrm{Xu},{ }^{a} \mathrm{Xin} \mathrm{Xu},{ }^{a} \mathrm{Chao} \mathrm{Fu},{ }^{a}$ Jinxuan Lin, ${ }^{b}$ \\ Shixun $\mathrm{Xu},{ }^{a}$ Qiang $\mathrm{Li}^{a}{ }^{a}$ and Haimin Lei*, ${ }^{*}$ \\ ${ }^{a}$ School of Chinese Pharmacy, Beijing University of Chinese Medicine; ${ }^{b}$ Department of Pathology, Beijing University \\ of Chinese Medicine; Beijing 100102, China: and ${ }^{c}$ Institute of Materia Medica, Chinese Academy of Medical Sciences \\ Peking Union Medical College; Beijing 100050, China.
}

Received June 5, 2013; accepted August 5, 2013

A new heptapeptide GAGPHGG (OC1) was isolated from Carapax trionycis which was a traditional Chinese medicine (TCM) used for treatment of hepatic diseases. The structure of OC1 was characterized by MS, NMR techniques, together with amino acid sequence analysis. The hepatoprotective activity of OC1 was evaluated in vivo using the $\mathrm{CCl}_{4}$-induced acute liver injury model. Combining the pathological examination and the biochemical assays, $\mathrm{OC} 1(0.34 \mathrm{mg} / \mathrm{kg}$, hypodermic injection) displayed better hepatoprotective effect than bifendate $(100 \mathrm{mg} / \mathrm{kg}$, intragastric administration) against the acute liver injury induced by carbon tetrachloride $\left(\mathrm{CCl}_{4}\right)$ in mice. Compared with the model group, $\mathrm{OC} 1$ could significantly suppress the increase of serum level of aminotransferase (alanine transaminase (ALT) and aspartate aminotransferase (AST)), decrease the formation of malondialdehyde (MDA) and elevate the activity of glutathione peroxidase (GSH-Px) in liver $(p<0.01)$. And the acute toxic test showed that median lethal dose $\left(\mathrm{LD}_{50}\right)$ of $\mathrm{OC1} \mathrm{exceeded} 6.8 \mathrm{mg} / \mathrm{kg}$, via hypodermic injection in mice.

Key words peptide; Carapax trionycis; acute liver injury; hepatoprotective activity; traditional Chinese medicine; acute toxicity

Carapax trionycis, originated from the shell of Trionyx sinensis Wiegmann, is well known as 'Bie-Jia' in China and used to reduce masses and nodulations, and relieve consumptive fever in traditional Chinese medicine (TCM). ${ }^{1)}$ Combined with some other herbs, it is applied for treatment of chronic liver fibrosis and hepatic cirrhosis. ${ }^{2}$ Bioactive peptides have attracted increasing attention from researchers because of their various properties as natural materials in functional food and for applications in medicine. ${ }^{3-6)}$ Based on different compositions and sequences of amino acid, these peptides may display various effects, such as immunomodulatory, antioxidation and hepatoprotective activities. ${ }^{7-10)}$ Carapax trionycis is a rich source of peptides; both the extractive and pure peptides of Carapax trionycis displaying well hepatoprotective effects have recently been reported as major active components of Carapax trionycis. ${ }^{11-15)}$

As part of our continuing research on bioactive peptides from TCM, a new heptapeptide was purified from aqueous extract of Carapax trionycis. Its structure was identified by high resolution-electrospray ionization (HR-ESI)-MS, amino acid sequence analysis, one-dimensional (1D)- and two-dimensional (2D)-NMR assays. Furthermore, the hepataprotective effect of this peptide was evaluated on acute hepatic injury mice which were induced by $\mathrm{CCl}_{4}$.

\section{Results and Discussion}

Purification and Identification of Heptapeptide As described in Experimental Part, the $80 \%$ ethanol precipitation was further purified by repeated ion exchanger chromatography (IEC), size-exclusion chromatography (SEC) and reverse-phase octadecylsilica (ODS) column chromatography. Finally, a single peak fraction monitored by HPLC (UV detection at $230 \mathrm{~nm}$ ) was collected and lyophilized, named OC1.

The authors declare no conflict of interest.

* To whom correspondence should be addressed. e-mail: hm lei@126.com
The purity of OC1 was $>98 \%$ by HPLC analysis. RP-HPLC chromatograms of key fractions during OC1's purified process were shown in Fig. 1.

OC1 was obtained as a white amorphous powder. Its molecular formula was assigned as $\mathrm{C}_{22} \mathrm{H}_{33} \mathrm{~N}_{9} \mathrm{O}_{8}$ on the basis of the positive electrospray ionization time-of-flight mass (ESITOF-MS $)\left[\mathrm{m} / \mathrm{z} 552.2530\left([\mathrm{M}+\mathrm{H}]^{+}\right)\right]$and in combination with the ${ }^{13} \mathrm{C}$-NMR spectrum (Table 1). As the smallest molecular weight of amino acid was glycine (Gly, $\mathrm{m} / \mathrm{z}$ 75.0520), we could infer that $\mathbf{O C} 1$ consisted of no more than 7 amino acid residues. Then the primary sequence of OC1 was confirmed to be Gly-Ala-Gly-Pro-His-Gly-Gly (GAGPHGG) via the amino acid sequence analysis. In the ${ }^{1} \mathrm{H}-\mathrm{NMR}$ spectrum, there existed only one methyl proton $\delta_{\mathrm{H}} 1.32(3 \mathrm{H}, \mathrm{d}, J=7.0 \mathrm{~Hz})$, which was connected with $\delta_{\mathrm{C}} 16.9$ (C-18) due to ${ }^{13} \mathrm{C}-\mathrm{NMR}$ and heteronuclear single quantum coherence (HSQC) spectra. Combined with the significant ${ }^{1} \mathrm{H}-{ }^{1} \mathrm{H}$ correlation spectroscopy (COSY) and heteronuclear multiple bond connectivity (HMBC) correlations (Fig. 2), this methyl group was connected to methyne $\delta_{\mathrm{H}} 4.34(1 \mathrm{H}, \mathrm{d}, J=7.0 \mathrm{~Hz})$ with $\delta_{\mathrm{C}} 49.6$ (C-3) which was assignable to the alanyl moiety. Similarly, one pyrrolidine group $\left[\delta_{\mathrm{H}} 3.52(2 \mathrm{H}, \mathrm{t}, J=7.0,13.5 \mathrm{~Hz})\right.$ with $\delta_{\mathrm{C}} 47.1$ $(\mathrm{C}-7), \delta_{\mathrm{H}} 1.90,1.83($ each $1 \mathrm{H}, \mathrm{m})$ with $\delta_{\mathrm{C}} 24.4(\mathrm{C}-8), \delta_{\mathrm{H}} 2.14$, 1.71 (each $1 \mathrm{H}, \mathrm{m})$ with $\delta_{\mathrm{C}} 29.4(\mathrm{C}-9), \delta_{\mathrm{H}} 4.30(1 \mathrm{H}, \mathrm{m})$ with $\delta_{\mathrm{C}}$ 60.6 (C-10)] was assignable to the prolyl moiety. (1H-Imidazol-4-yl) ethyl unit $\left[\delta_{\mathrm{H}} 4.64(1 \mathrm{H}, \mathrm{m})\right.$ with $\delta_{\mathrm{C}} 52.5(\mathrm{C}-12), \delta_{\mathrm{H}}$ $3.23,3.13($ each $1 \mathrm{H}, \mathrm{m})$ with $\delta_{\mathrm{C}} 26.0(\mathrm{C}-19)$, and $\delta_{\mathrm{H}} 7.23(1 \mathrm{H}, \mathrm{s})$ with $\delta_{\mathrm{C}} 117.4(\mathrm{C}-21), \delta_{\mathrm{H}} 8.52(\mathrm{~s}, 1 \mathrm{H})$ with $\left.\delta_{\mathrm{C}} 133.6(\mathrm{C}-22)\right]$ was assignable to the histidyl moiety.

In addition, the HMBC correlations (Fig. 2) between alanyl CH-5 $\left[\delta_{\mathrm{H}} 3.96,4.05\right.$ (each $1 \mathrm{H}, \mathrm{d}, J=17.0 \mathrm{~Hz}$ ) ] and carbonyl carbon in glycyl $\delta_{\mathrm{C}} 175.1(\mathrm{C}-4)$, correlations between histidyl CH-14 $\left[\delta_{\mathrm{H}} 3.87(2 \mathrm{H}, \mathrm{s})\right]$ and carbonyl carbon in glycyl $\delta_{\mathrm{C}}$ 172.1 (C-13) confirmed -Ala-Gly- unit and the -His-Gly- unit, respectively. ESI-TOF-MS also exhibited fragment ion peak at 

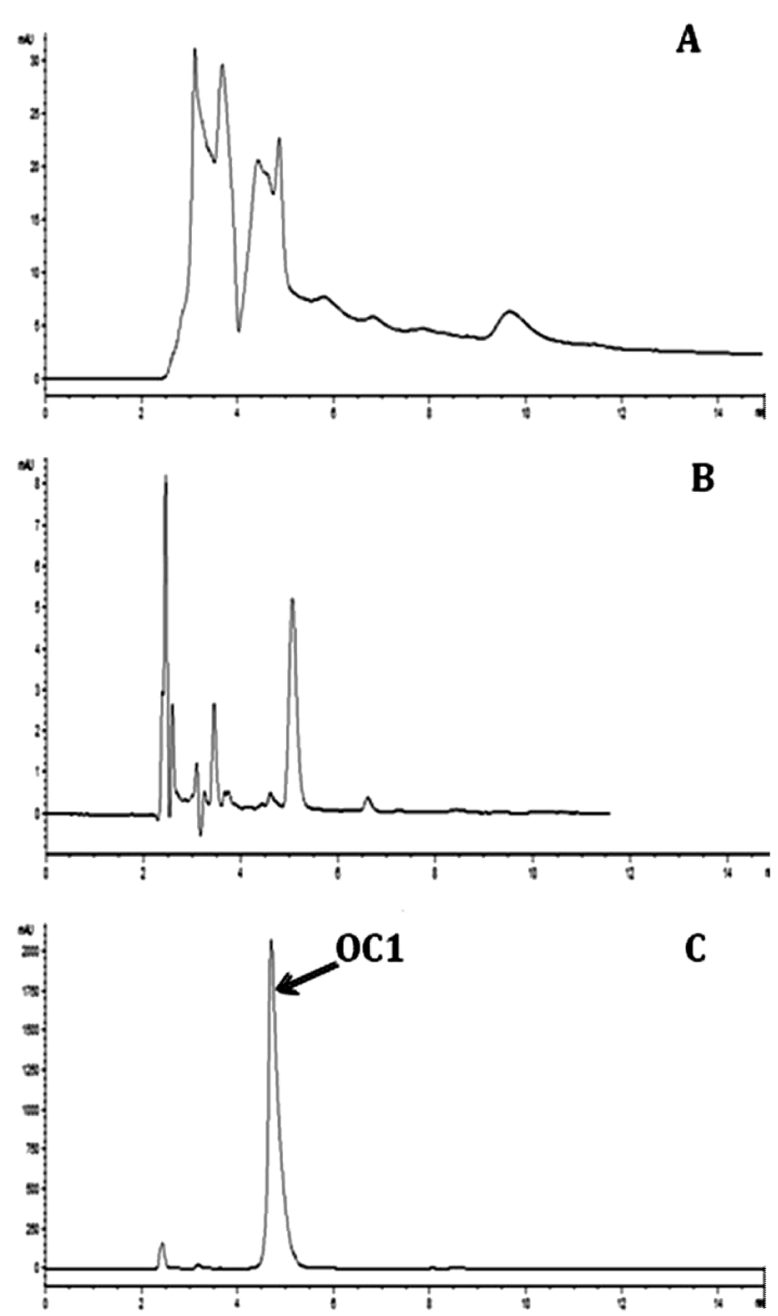

Fig. 1. RP-HPLC Chromatograms of OC1's Purified Process

(A) $80 \%$ ethanol precipitation. (B) Key fraction after IEC chromatography. (C) One single peak fraction (OC1) after SEC and ODS chromatography.

$m / z$ 129.0684 $[\mathrm{M}+\mathrm{H}]^{+}$and $m / z$ 424.1951 $[\mathrm{M}+\mathrm{H}]^{+}$, which supported the presences of -Ala-Gly- unit and -Gly-Pro-His-GlyGly unit, respectively.

Furthermore, interpretation of nuclear Overhauser effect spectroscopy (NOESY) spectrum revealed correlations be-

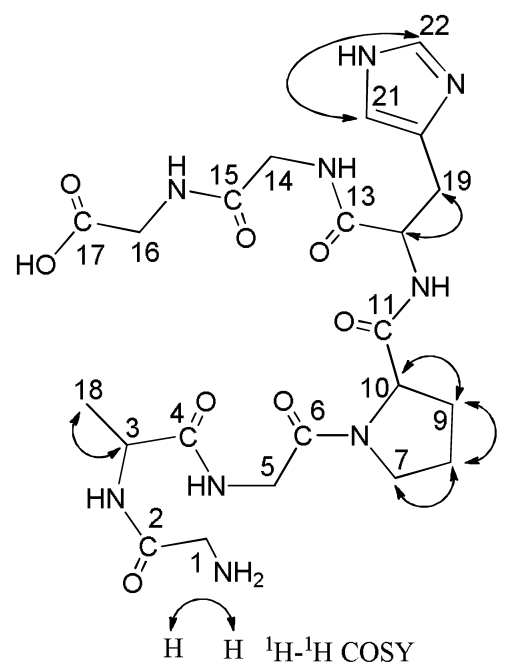

Table 1. ${ }^{1} \mathrm{H}-(500 \mathrm{MHz})$ and ${ }^{13} \mathrm{C}-(125 \mathrm{MHz})$ NMR Data of $\mathbf{O C} \mathbf{1}$ in $\mathrm{D}_{2} \mathrm{O}$ ( $\delta$ in ppm, $J$ in $\mathrm{Hz}$ )

\begin{tabular}{|c|c|c|}
\hline Position & $\delta_{\mathrm{C}}$ & $\delta_{\mathrm{H}}$ \\
\hline 1 & 40.4 & $3.75(2 \mathrm{H}, \mathrm{s})$ \\
\hline 2 & 166.6 & - \\
\hline 3 & 49.6 & $4.34(1 \mathrm{H}, \mathrm{d}, J=7.0 \mathrm{~Hz})$ \\
\hline 4 & 175.1 & - \\
\hline 5 & 41.7 & $3.96,4.05($ each $1 \mathrm{H}, \mathrm{d}, J=17.0 \mathrm{~Hz})$ \\
\hline 6 & 169.4 & - \\
\hline 7 & 47.1 & $3.52(2 \mathrm{H}, \mathrm{t}, J=7.0,13.5 \mathrm{~Hz})$ \\
\hline 8 & 24.4 & $1.90,1.83($ each $1 \mathrm{H}, \mathrm{m})$ \\
\hline 9 & 29.4 & $2.14,1.71($ each $1 \mathrm{H}, \mathrm{m})$ \\
\hline 10 & 60.6 & $4.30(1 \mathrm{H}, \mathrm{m})$ \\
\hline 11 & 174.6 & - \\
\hline 12 & 52.5 & $4.64(1 \mathrm{H}, \mathrm{m})$ \\
\hline 13 & 172.1 & - \\
\hline 14 & 42.4 & $3.87(2 \mathrm{H}, \mathrm{s})$ \\
\hline 15 & 174.6 & - \\
\hline 16 & 41.5 & $3.88(2 \mathrm{H}, \mathrm{s})$ \\
\hline 17 & 174.6 & - \\
\hline 18 & 16.9 & $1.32(3 \mathrm{H}, \mathrm{d}, J=7.0 \mathrm{~Hz})$ \\
\hline 19 & 26.0 & $3.23,3.13($ each $1 \mathrm{H}, \mathrm{m})$ \\
\hline 20 & 128.5 & - \\
\hline 21 & 117.4 & $7.23(1 \mathrm{H}, \mathrm{s})$ \\
\hline 22 & 133.6 & $8.52(1 \mathrm{H}, \mathrm{s})$ \\
\hline
\end{tabular}

tween glycyl CH-1 and glycyl CH-5, between glycyl CH-1 and procyl $\mathrm{CH}-7$, between glycyl $\mathrm{CH}-5$ and procyl $\mathrm{CH}-7$, which indicated the near space distance of first Gly- with the third Gly- and Prolyl in the Gly-Ala-Gly-Pro unit. Another longrange correlation was also observed in the -Gly-Pro-His-GlyGly unit; the correlations between glycyl $\mathrm{CH}-5$ and glycyl $\mathrm{CH}-14$, between glycyl $\mathrm{CH}-5$ and glycyl $\mathrm{CH}-16$ suggested a near space distance of the third, the sixth and the seventh glycyl.

Therefore, all of the above evidences fully supported the assigned structure of OC1 (Fig. 3); its secondary structure seemed to be an inverted character 'S.' However, the exactly secondary structure of this peptide still needs three-dimensional (3D)-NMR, X-ray research and other techniques.

Peptide Synthesis OC1 was custom-synthesized accord-

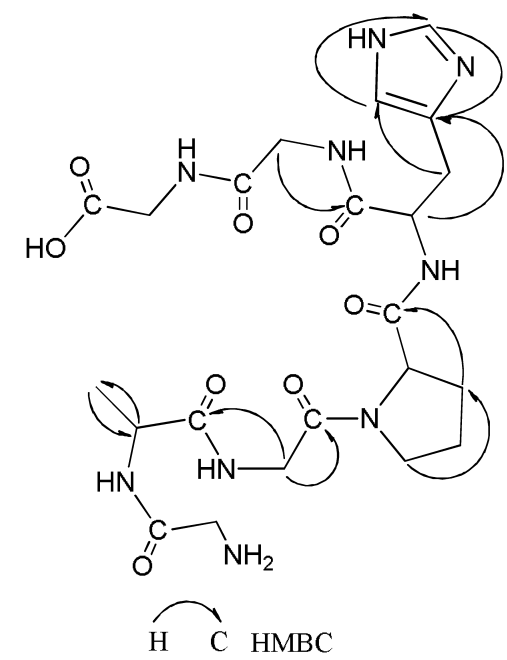

Fig. 2. Key ${ }^{1} \mathrm{H}-{ }^{1} \mathrm{H}$ COSY and $\mathrm{HMBC}$ Correlations of $\mathbf{O C} \mathbf{1}$ 


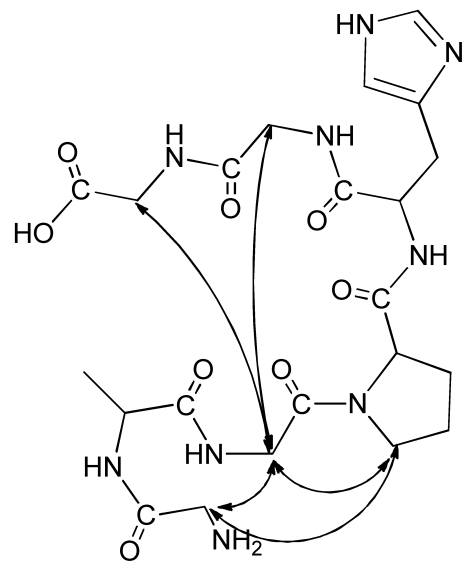

Fig. 3. Key NOESY Correlations of OC1

ing to their sequences by Shanghai Science Peptide Biological Technology Corporation (Shanghai, China) via a standard Fmoc solid-phase strategy. The purity of the synthetic OC1 was more than $98 \%$. The ESI-TOF-MS data of the synthetic peptide was consistent with expected masses after synthesis. Both of HPLC and HRMS data proved that structures of synthetic OC1 and natural OC1 were identical.

The Hepatoprotective Effect of OC1 The effects of OC1 on the activities of alanine transaminase (ALT), aspartate aminotransferase (AST), glutathione peroxidase (GSH)-Px and the level of malondialdehyde (MDA) in $\mathrm{CCl}_{4}$-induced hepatotoxicity mice were shown in Table 2. Serum ALT and AST levels, which were often used as biochemical markers to evaluate hepatic injury, significantly increased in model group compared to normal group $(p<0.01)$. While experimental results showed that serum aminotransferase (ALT and AST) activities of OC1 and bifendate treatment groups were markedly inhibited than the model group $(p<0.01)$. For $\mathrm{CCl}_{4}$-induced hepatotoxicity, the product of lipid peroxidation (MDA) was accumulated in damaged liver. ${ }^{16)}$ An increase in MDA levels in the liver suggested that the peroxidation leading to tissue injury and failure of the antioxidant-defense mechanisms was enhanced; subsequently, activity of antioxidant enzymes was decreased. ${ }^{16,17)}$ GSH-Px, one kind of antioxidant enzymes, was an important enzyme catalyzed the reduction of hydroperoxides to non-toxic products and terminated the chain reaction of lipid peroxidation. ${ }^{18,19)}$ As shown in Table 2, both low and high dose treatment of OC1 significantly decreased level of MDA and increased activity of GSH-Px in liver $(p<0.01)$, when compared to model group. Notably, high dose OC1 $(0.34 \mathrm{mg} / \mathrm{kg}$, hypodermic injection (i.h.)) treated group displayed much better effect than bifendate treatment for all of the biochemical tests in mice.
Moreover, the protective effects exerted by OC1 against $\mathrm{CCl}_{4}$-induced hepatotoxicity were further confirmed by conventional histological assessment (Fig. 4). Normal liver lobular architecture and cell structure were shown in normal group (Fig. 4A). The stained sections of model group showed apparently morphological changes including severe hepatocellular hydropic degeneration, many ballooned hepatocytes, and spotty necrosis around the central vein (Figs. 4B, C). However, $\mathrm{CCl}_{4}$-intoxicated mice pretreated with $100 \mathrm{mg} / \mathrm{kg}$ bifendate (Fig. 4D) and 0.17, $0.34 \mathrm{mg} / \mathrm{kg}$ OC1 (Figs. 4E, F) showed moderate hypertrophy of hepatocytes with obviously decreasing the injured area, necrotic cells and ballooning degeneration.

The results indicated that $\mathbf{O C} 1$ could attenuate the elevation of AST, ALT, MDA levels, and increase GSH-Px activity in mice induced by $\mathrm{CCl}_{4}(p<0.01)$. The significant hepatoprotective effect of OC1 was further supported by the evaluation of liver histopathology in mice. Its hepatoprotective effect may be related to its increasing antioxidant activity and inhibiting lipid peroxidation. More importantly, it was interesting that the high dose of OC1 treatment displayed even better hepatoprotective activity than bifendate-treated group. Based on the above evidences, OC1 may be one of the effective ingredients of Carapax trionycis with a potent hepatoprotective effect in clinical use.

Acute Toxic Test in Vivo To exam whether the given doses selected during hepatoprotective experiment were in a safe threshold values, acute toxic test of OC1 was carried on Kunming mice. The relative body weight loss was utilized as a measure of toxicity. ${ }^{20,21)}$ The mice were randomly grouped on the basis of the body weight. At the beginning of administration, the weight showed no significant difference between each group $(p>0.05)$. After administrating tenfold of high preventive dose of $\mathbf{O C 1}(6.8 \mathrm{mg} / \mathrm{kg}$, i.h.), there were no mortality in each group and no signs of general clinical symptoms of toxicity or abnormal behavior during two weeks. At the end of the experiment, there were no significant differences in body weights between treatment and control groups (Fig. 5).

\section{Conclusion}

In summary, present study demonstrated the isolation, purification and the structure determination of a new heptapeptide OC1 from Carapax trionycis with its hepatoprotective activity and acute toxicity in vivo. Pharmacological results, which have been supported by the evaluation of biochemical assays and liver histopathology in mice, indicate that $\mathbf{O C} 1$ has significant protective effect against acute hepatotoxicity induced by $\mathrm{CCl}_{4}$. Further studies on action mechanism and anti-experimental hepatic fibrosis effects of $\mathbf{O C} \mathbf{1}$ are in progress.

Table 2. Effects of $\mathbf{O C 1}$ Pretreatment on $\mathrm{CCl}_{4}$-Induced Alteration in Serum Aminotransferase and Hepatic GSH-Px Activities and MDA Level in Mice

\begin{tabular}{cccccc}
\hline \hline Group & Dose $(\mathrm{mg} / \mathrm{kg})$ & ALT $(\mathrm{U} / \mathrm{L})$ & AST $(\mathrm{U} / \mathrm{L})$ & GSH-Px $(\mathrm{U} / \mathrm{mg})$ & MDA $(\mathrm{nmol} / \mathrm{g})$ \\
\hline Normal group & - & $36.2 \pm 9.6$ & $141.4 \pm 11.3$ & $317.6 \pm 26.5$ & $1.8^{2} \pm 1.2$ \\
Model group & - & $346.7 \pm 46.2^{* *}$ & $286.8 \pm 42.2^{* *}$ & $102.3 \pm 14.7^{* *}$ & $11.5 \pm 2.5^{* *}$ \\
Bifendate group & 100 & $92.4 \pm 35.3^{\# \#}$ & $156.2 \pm 34.1^{\# \#}$ & $267.2 \pm 32.1^{\text {\#\# }}$ & $6.5 \pm 1.7^{\text {\#\# }}$ \\
OC1 & 0.17 & $123.2 \pm 19.7^{\# \#}$ & $187.0 \pm 37.6^{\# \#}$ & $296.8 \pm 18.3^{\text {\# }}$ & $5.3 \pm 1.3^{\text {\#\# }}$ \\
OC1 & 0.34 & $86.5 \pm 28.7^{\# \#}$ & $148.6 \pm 31.3^{\# \#}$ & $308.3 \pm 38.5^{\text {\#\# }}$ & $2.8 \pm 1.4^{\# \#}$ \\
\hline
\end{tabular}

Compared with normal group: ${ }^{*} p<0.05,{ }^{*} p<0.01$. ${ }^{\#}$ Compared with model group: ${ }^{\#} p<0.05,{ }^{\#} p<0.01$. All data are expressed as mean \pm S.D. $(n=10)$. 

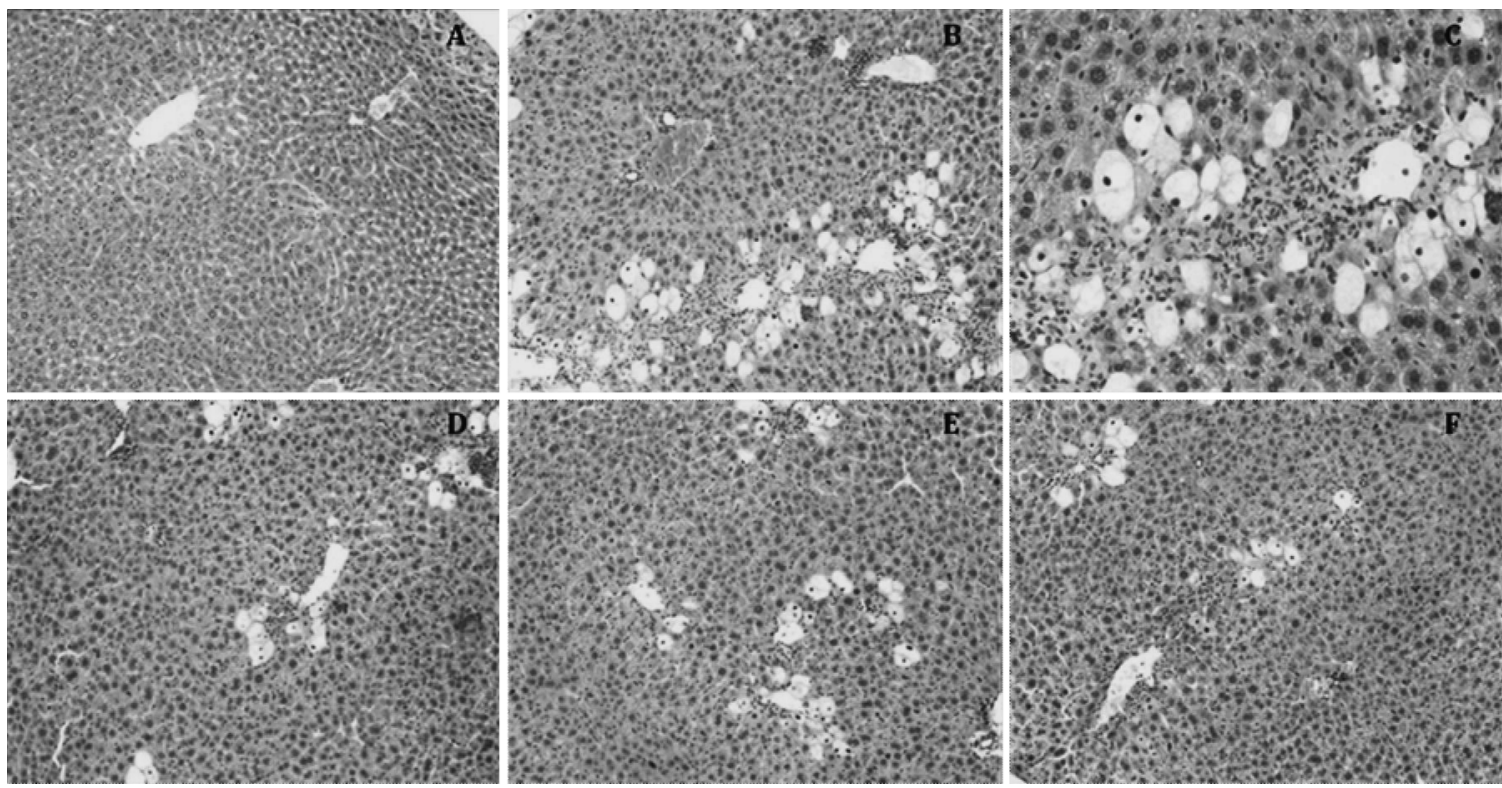

Fig. 4. Hepatoprotective Effect of OC1 by HE Staining

(A) Normal group $(\times 100)$. (B) Model group $(\times 100)$. (C) Model group $(\times 200)$. (D) Bifendate-treated group $(\times 100)$. (E) Low dose of $\mathbf{O C} \mathbf{1}$ group $(\times 100)$. (F) High dose of $\mathbf{O C} 1$ group $(\times 100)$.

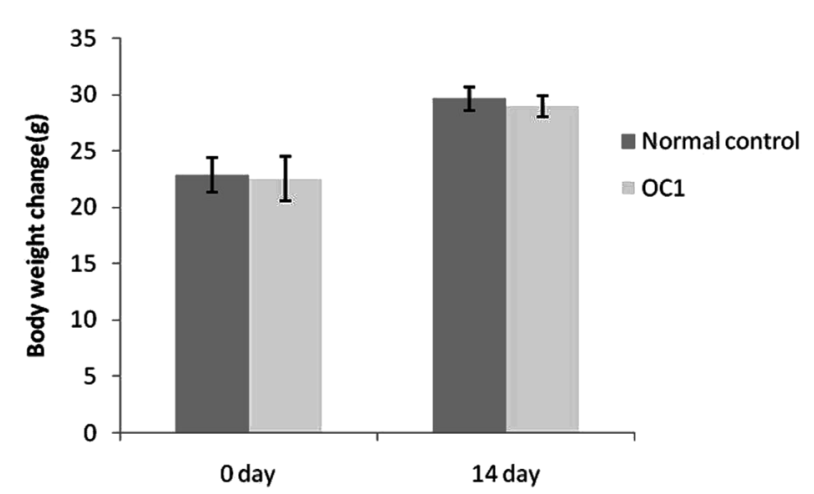

Fig. 5. Body Weights Change of Each Group at the First Day (Day 0) and the Last Day (Day 14) after Administrating OC1 $(6.8 \mathrm{mg} / \mathrm{kg}$, i.h.)

Compared with control group: ${ }^{*} p<0.05$. All data were expressed as mean \pm S.D. $(n=20)$.

\section{Experimental}

General Experimental Procedures Mass spectra were obtained by using Q-TOF $\left(\mathrm{ESI}^{+}\right)$with an LC Autosampler Device: Waters 2695 Instrument (New York, NY, U.S.A.). The mobile phase was composed of acetonitrile (A) and $0.1 \%$ TFA $-\mathrm{H}_{2} \mathrm{O}$ (B) with gradient elution (0-30 min, linear 3-20\% A) at a flow rate of $1.0 \mathrm{~mL} / \mathrm{min}$ with detection at $230 \mathrm{~nm}$. Column: Shodex Asahipak ODP-50 6D $(150 \times 6 \mathrm{~mm}, 5 \mu \mathrm{m}$, No. P211018). The injection volume was $10 \mu \mathrm{L}$. The column temperature was maintained at $25^{\circ} \mathrm{C}$. Amino acid sequence of purified peptide was analyzed with the use of the 492 protein sequencer (Biosystems Inc., U.S.A.). ${ }^{1} \mathrm{H}-\mathrm{NMR},{ }^{13} \mathrm{C}-\mathrm{NMR}$, ${ }^{1} \mathrm{H}-{ }^{1} \mathrm{H}$ COSY, HSQC, HMBC, and NOESY assays were recorded on a BRUKER AVANCE 500 NMR Spectrometer (Fällanden, Switzerland) and chemical shifts are reported in (ppm). IEC column was packed with type 732 strong acid styrene cation exchanger (Tianjin Nankai Chemical Industry, China), SEC column with Sephadex LH-20 (Pharmacia Co., U.S.A.), ODS (YMC Co., Ltd., Kyoto, Japan). Bifendate drop pill (1.5 mg bifendate per pill, No. H11020979) was provided by Peking Union Medical Pharmaceutical Factory (Beijing, China). All other reagents were of analytical grade. Kunming mice (Beijing Vital River Laboratory Animal Technology Co., Ltd., China) were kept under standard laboratory conditions (tap water, constant room temperature $22^{\circ} \mathrm{C}$ ). All animal experiments were preformed in accordance with the 'Regulation for the Administration of Affairs Concerning Experimental Animals' (State Council of China, 1988). And all experimental procedures with animals used in the present study were reviewed and approved by the Beijing University of Chinese Medicine Experimental Animal Manage Committee.

Material The dried Carapax trionycis were collected from China Medical Materials Group Ltd., China, in July 2010, and identified by Prof. Chun-Sheng Liu (Beijing University of Chinese Medicine). An authentic sample (No. 100705) was kept in School of Chinese Pharmacy, Beijing University of Chinese Medicine.

Extraction and Isolation Water-extraction and alcoholprecipitation method was used for the isolation procedure. Carapax trionycis $(1.0 \mathrm{~kg})$ were extracted with distilled water $(3 \times 10.0 \mathrm{~L})$ three times under reflux, $1.5 \mathrm{~h}$ for each time. After filtration, the aqueous solution was concentrated under $40^{\circ} \mathrm{C}$ to a density of $1.05 \mathrm{~g} / \mathrm{mL}$. Then the aqueous fraction was partitioned with ethanol to gradually yield 20\%,60\%, $80 \%$ ethanol fractional precipitations. Biuret reaction was used to trace the protein, and then the positive fraction was primarily collected and lyophilized. The vacuum freeze-drying process was carried out on laboratory freeze dryer (Beijing Boyikang Laboratory Instrument Co., China).

Column chromatography was performed on IEC, SEC and ODS for the further purification. The lyophilized powder of $80 \%$ ethanol precipitation $(16 \mathrm{~g})$ was dissolved in $50 \mathrm{~mm}$ HAc-NaAc buffer $(96 \mathrm{~mL}, \mathrm{pH} 4.5)$ and loaded onto IEC column $(80 \mathrm{~cm} \times 4 \mathrm{~cm})$, which was previously equilibrated with $50 \mathrm{~mm} \mathrm{NaAc}-\mathrm{HAc}$ buffer ( $\mathrm{pH}$ 4.5). After sample subjected, the column was eluted with $50 \mathrm{~mm} \mathrm{NaAc}-\mathrm{HAc}$ buffer $(\mathrm{pH} 4.5$ ) 
until no biuret reaction appeared and was then eluted with $\mathrm{NaCl}$ buffer (0 to $1.0 \mathrm{M}$ ) to obtain twelve fractions (Frs. 1-12). Fr. $7(59 \mathrm{mg})$, showed positive biuret reaction and well HPLC peaks, was fractionated on SEC and ODS eluted with a step gradient of $\mathrm{H}_{2} \mathrm{O}-\mathrm{MeOH}(1: 0 \rightarrow 0: 1)$. Similarly, fractions with positive biuret reaction and desire HPLC peaks were pooled and lyophilized during this process. All above treatments were done blow $40^{\circ} \mathrm{C}$. Finally, the pure peptide obtained was named OC1 (6 mg). White solid, mp $183.6-184.3^{\circ} \mathrm{C}$. UV $\lambda_{\max }$ $\left(\mathrm{H}_{2} \mathrm{O}\right) \mathrm{nm}(\log \varepsilon): 205$ (4.23), 230 (3.08). Amino acid sequence analysis: GAGPHGG. ${ }^{1} \mathrm{H}-$ and ${ }^{13} \mathrm{C}-\mathrm{NMR}$ : see Table 1 . Key ${ }^{1} \mathrm{H}-{ }^{1} \mathrm{H}$ COSY and HMBC correlations $\left(\mathrm{D}_{2} \mathrm{O}, 500 \mathrm{MHz}\right)$ : see Fig. 2. Key NOESY correlations $\left(\mathrm{D}_{2} \mathrm{O}, 500 \mathrm{MHz}\right)$ : see Fig. 3. HR-ESI-MS m/z: $552.2530\left([\mathrm{M}+\mathrm{H}]^{+}, \mathrm{C}_{22} \mathrm{H}_{33} \mathrm{~N}_{9} \mathrm{O}_{8}\right.$, Calcd for 552.2525).

Synthesis of OC1 OC1 $(0.15 \mathrm{~g})$ prepared for the hepatoprotective evaluation was synthesized with the peptide synthesizer PS3 (Rainin Instrument Co., Inc., U.S.A.) using the solid phase method. Fmoc-amino acids were successively coupled in the presence of $o$-benzotriazol-1-yl- $N, N, N^{\prime}, N^{\prime}$ tetramethyluronium hexafluorophosphate (HBTU). Peptide, after deprotection, was purified by using the above isolation methods. The purity of synthesized OC1 was more than $98 \%$. White solid, mp $183.9-184.7^{\circ} \mathrm{C}$. HR-ESI-MS $\mathrm{m} / \mathrm{z}$ : 552.2531 $\left([\mathrm{M}+\mathrm{H}]^{+}, \mathrm{C}_{22} \mathrm{H}_{33} \mathrm{~N}_{9} \mathrm{O}_{8}\right.$, Calcd for 552.2525).

The Effect of OC1 on Acute Hepatic Injury Mice Induced by $\mathbf{C C l}_{4}$ For the hepatotoxicity study, $\mathrm{CCl}_{4}$ was used to induce acute liver damage according to references with slight modifications. ${ }^{22}$ Bifendate, a classic hepatoprotective agent used to treat various liver diseases, was selected as a reference compound in our acute liver injury studies. ${ }^{23,24)}$ Fifty male Kunming mice (weight $22 \pm 3 \mathrm{~g}$ ) were randomly divided into normal group, model group, bifendate group, low OC1 dose group, and high OC1 dose group $(n=10)$, respectively. Mice in the low and high OC1 (dissolved in physiological saline) dose groups received $\mathbf{O C} 1$ of 0.17 and $0.34 \mathrm{mg} / \mathrm{kg}$ via hypodermic injection i.h. every other day for $8 \mathrm{~d}$, respectively; bifendate group was administrated with $100 \mathrm{mg} / \mathrm{kg}$ of bifendate via gavage (i.g.), once a day for eight consecutive days; simultaneously, normal and model groups were administrated with physiological saline. Two hours after the final administration, mice from model, bifendate, low and high dose of OC1 groups were intraperitoneally injected with $0.1 \% \mathrm{CCl}_{4} /$ olive oil solution at a dose of $10 \mathrm{~mL} / \mathrm{kg}$ on the 8 th day. However, normal group was intraperitoneally injected with $10 \mathrm{~mL} /$ $\mathrm{kg}$ of olive oil. Twenty four hours after $\mathrm{CCl}_{4}$ administrations, the blood was collected from the ophthalmic veins and serum was separated by centrifugation at $3000 \mathrm{rpm}$ at $4^{\circ} \mathrm{C}$ for $20 \mathrm{~min}$. Serum ALT and AST levels were measured with an AU2700 automatic biochemical analyzer (Olympus, Japan). Meanwhile, the mice were sacrificed and the liver were excised and weighed. Then a portion of mice liver was excised and homogenized immediately in $0.1 \mathrm{~g} / \mathrm{mL}$ ice-cold physiological saline. The homogenate was centrifuged at $1000 \times \boldsymbol{g}$ for $10 \mathrm{~min}$, and then the supernatant was collected for further MDA level and GSH-Px activity analysis by using commercial reagent kits from Nanjing Jiancheng Bioengineering Institute (Nanjing, China) according to the instruction manuals. Samples of other liver were fixed in $10 \%$ neutral buffered formalin, embedded in paraffin, sectioned at $4 \mathrm{~mm}$, and processed according to the hematoxylin and eosin (HE) staining protocol.
Acute Toxicity According to our previous studies, ${ }^{25,26)}$ Kunming mice of both sexes, weighing $22 \pm 2 \mathrm{~g}$, were divided into two groups of 20 animals matched in weight and size. The mice were deprived of food for $12 \mathrm{~h}$ but allowed free access to tap water before the experiments. Then one group of 20 mice of both sexes were administered a single dose of OC1 $(6.8 \mathrm{mg} / \mathrm{kg}$, i.h.). The other 20 mice, control group, were intraperitoneally injected with physiological saline. The general behavior of mice was observed continuously for $1 \mathrm{~h}$ after the treatment and then intermittently for $4 \mathrm{~h}$, and thereafter over a period of $24 \mathrm{~h}$. The mice were further observed for up to $14 \mathrm{~d}$ following treatment for any signs of toxicity and deaths, and the latency of death. Behavioral, toxic effects and mortality response were recorded.

Statistical Analysis All data are expressed as mean \pm S.D. Data analysis was carried out using SAS software, version 8.1 (SAS Institute, Cary, NC, U.S.A.). Statistically significant differences between the samples were evaluated by Student's $t$-test and $p<0.05$ was considered significant.

Acknowledgments This study was financially supported by the National Natural Science Foundation of China (No. 81073017) and the Innovation Team Project Foundation of Beijing University of Chinese Medicine (Lead Compound Discovering and Developing Innovation Team Project Foundation, No. 2011-CXTD-15).

\section{References}

1) Chinese Pharmacopoeia Commission, "Chinese Pharmacopoeia," Part I, 2010, p. 266.

2) Guo S. G., Zhang W., Jiang T., Dai M., Zhang L. F., Meng Y. C., Zhao L. Y., Niu J. Z., World J. Gastroenterol., 10, 1487-1494 (2004).

3) Zhong J., Wang W., Yang X., Yan X., Liu R., Peptides, 39, 1-5 (2013).

4) Wang G., Luo J. G., Yang M. H., Wang X. B., Kong L. Y., Chem. Pharm. Bull., 61, 489-495 (2013).

5) Ding G., Chen A. J., Lan J., Zhang H., Chen X., Liu X., Zou Z., Chem. Biodivers., 9, 1205-1212 (2012).

6) Zhang T., Li Y. H., Miao M., Jiang B., Food Chem., 128, 28-33 (2011).

7) Zhang J. G., Cong B., Jia X. X., Li H., Li Q. X., Ma C. L., Feng Y., Int. Immunopharmacol., 11, 1685-1690 (2011).

8) Feng X., Su X., Wang F., Wei J., Wang F., Cao R., Zhou B., Mao X., Zheng Q., Chen P., Peptides, 31, 1562-1568 (2010).

9) Li Y. W., Li B., J. Theor. Biol., 318, 29-43 (2013).

10) Shi Y., Sun J., He H., Guo H., Zhang S., J. Ethnopharmacol., 117, 415-419 (2008).

11) Lei H. M., Patent PCT/CN2011/081620, 1st November 2011.

12) Gao J. R., Liu Y. W., Li C. Y., Yao H. P., Zhang C. Z., Chen J. W., Shao Z. H., Liu J. W., Cai W. M., Ding Y. X., Zhu Y. F., Tang Y. P., Hu C. L., Shi J. N., Hu Z. L., Zhang H. Q., Yang L., Zhonghua Gan Zang Bing Za Zhi, 18, 346-352 (2010).

13) Hu C. L., Tang Y. P., Liu Y. W., Journal of Chinese Pharmaceutical Sciences, 21, 132-135 (2012)

14) Tang Y. P., Xu L. Y., Liu Y. W., Journal of Hubei University of Chinese Medicine, 13, 44-46 (2011).

15) Tang Y., Hu C., Liu Y., J. Ethnopharmacol., 148, 69-73 (2013).

16) Cheng N., Ren N., Gao H., Lei X., Zheng J., Cao W., Food Chem. Toxicol., 55, 234-240 (2013).

17) Naik S. R., Indian Drugs, 40, 501-516 (2003).

18) Naik S. R., Panda V. S., Liver Int., 27, 393-399 (2007).

19) Jung K., Henke W., Free Radic. Biol. Med., 20, 613-617 (1996).

20) Wang P. L., Zhang Y. Z., Xu X., Li Q., Zhang H. G., Guo J., Pang 
D. D., Cheng Y. T., Lei H. M., Pharmazie, 68, 782-789 (2013).

21) Wu D., Gao Y., Chen L., Qi Y., Kang Q., Wang H., Zhu L., Ye Y., Zhai M., Peptides, 31, 850-864 (2010).

22) Gan D., Ma L., Jiang C., Wang M., Zeng X., Food Chem. Toxicol., 50, 2681-2688 (2012).

23) Shen X., Tang Y., Yang R., Yu L., Fang T., Duan J. A., J. Ethnopharmacol., 122, 555-560 (2009).
24) Jia X. Y., Zhang Q. A., Zhang Z. Q., Wang Y., Yuan J. F., Wang H. Y., Zhao D., Food Chem., 125, 673-678 (2011).

25) Wang P., She G., Yang Y., Li Q., Zhang H., Liu J., Cao Y., Xu X., Lei H., Molecules, 17, 4972-4985 (2012).

26) Wang P. L., Cheng Y. T., Xu K., Li Q., An Y. W., Wang W., Li Q. S., Han Q. J., Li Q., Zhang H. G., Lei H. M., Asian J. Chem., 25, 4885-4888 (2013). 